that they tell us more accurately than before what we and our fellows are like.

So what are the implications of the new data for the spread of AIDS? Will it now be possible to plug the numbers into a suitable mathematical model so as accurately to predict the future spread of AIDS in countries such as France and Britain? That expectation would be naive. As things are, uncertainties linked with the pathogenesis of AIDS, which may for example affect the definition of quantities such as 'incubation time', are probably as great as or even greater than those deriving from uncertainties of the behavioural data. In any case, what the world needs from a better description of the epidemiology of AIDS is not so much a precise estimate of its burden on health care services in decades ahead - the passage of time will sadly provide sufficient indicators of that - but an appreciation of the points at which changes in sexual behaviour may dramatically reduce the burden of AIDS on its potential victims and on society at large. In this connection, two features of this week's surveys obtrude: the relative promiscuity (compared with younger and older age groups) of people aged 35 to 45 , and the evidence (from the French survey) that while there has been an encouraging spread of the use of condoms among the very young, large proportions of those most at risk continue to scorn the use of the only safe prophylactic against HIV infection so far known.

What will happen now? There is a good chance that the new surveys, like all good research, will be powerful stimulants of other investigations. It goes without saying that these data collectively will also help with the simpler problems of understanding the spread of other sexually transmitted diseases, too many of which are resurgent in modern society. There is the strongest possible reason why those who support research, governments in particular, should support continuing studies in this field and do so in a generous spirit.

\section{Waldegrave's dilemma}

\section{Mr William Waldegrave should not be deterred from} consultation by his experience this week.

BRITISH science may not be what it used to be, but enthusiasm for reorganization remains apparently undimmed. So much is clear from the replies now trickling into the public domain from some of the many organizations invited to comment on the plan, early next year, to produce a white paper (policy statement) on research arrangements. Minor reorganizations happen all the time, of course, but if the promised white paper emerges, if it reflects in any way the radical ambitions of some of those who have commented upon it, and if it is then acted upon, British governments will have arranged for three major upheavals of public science in 30 years. But change - its pace and unpredictability has become part of the problem, not the solution. British science would be better off if its institutions were this time given an opportunity to evolve constructively.
This time the pressure for radical change comes about for an unexpected reason - Mr William Waldegrave's decision to invite suggestions on the white paper project from organizations including the government's own bodies active in the field. Some of these have now published what they have had to say. The results are revealing, if more of the respondents than of their subject matter. The government's own Advisory Council on Science and Technology (ACOST), which argues for radical change, wants a "coordinated national framework for research" and a new research council "for scientific knowledge" called CASK, to support "curiosity-driven research".

There may be something in the idea, but the language in which it is embedded and the quality of the argument on which it rests leave much to be desired. Must researchers be known as "research providers", for example? Is it true that the "inordinate time .... for peer review" is one of the objections to present arrangements for supporting basic research? Of course, if the "coordinated national framework" were sufficiently detailed, projects might be chosen by looking for appropriate keywords in the research grant applications. But would they necessarily be first-rate or even second-rate?

Waldegrave can easily slough off evidently pointless arguments such as these. He will find it more difficult, in the next few months, to keep at bay the clamour of those who would make the whole of the British research enterprise part of some yet to be defined industrial strategy. Yet that is the big danger; that having embarked on the laudable enterprise of looking again at the organization of research in Britain, Waldegrave will find himself lumbered with ideas whose only force is that they are advanced by powerful people.

\section{College admissions}

\section{Virginia education council says entering students should be able to read and calculate}

IT is increasingly the case that first year students at US colleges and universities require remedial courses in reading, writing and mathematics before they are fully able to take college-level courses. This absurd circumstance has occurred (in part) because of a political philosophy that says all students are entitled to a college education. Now, along comes the council of higher education for the State of Virginia with a remarkably sensible, if long overdue, suggestion for reducing the cost in dollars and time associated with teaching college students things they should have learned in high school.

Virginia's full-fledged colleges should raise their admissions standards, leaving students who are not prepared for college-level work to attend two-year community colleges where remedial courses more properly belong. It sounds so obvious. The sad part is that such a suggestion can be made seriously or deserve to be taken as novel. 